\title{
RESULTS OF THE APPLICATION OF INFOGRAPHS AS A TOOL IN UNIVERSITY TEACHING
}

\author{
M.A. Carabal-Montagud, V. Santamarina-Campos, L. Fuster López, \\ M.V. Esgueva López \\ Universitat Politècnica de València (SPAIN)
}

\begin{abstract}
This text analyses the result of the application of infographics as a teaching tool in university teaching. In this case, this study focuses on the analysis of the results obtained from this educational innovation used to deliver the subject "Introduction to the Conservation and Restoration of golds and polychromies" as part of the Degree in Conservation and Restoration of Cultural Heritage at the Universitat Politècnica de València.
\end{abstract}

Infographics are presented as a visual, attractive, didactic and dynamic ICT tool, considered to be very useful, as it contains complex content in diagrams, which follow current social visual codes and can provide a service applicable to many disciplines, if it focuses on the direction of information transfer in teaching.

The aim of this study is to assess the results obtained after the application of individual and group infographics, as an element of evaluation of content acquisition, combined with other teaching techniques. The students' own assessment is taken into account, focusing the study on whether it has been useful for their learning, if it helped them synthesize content and develop their practical and critical thinking.

Keywords: Infographics, University Teaching, Educational Innovation, ICT, Critical Thinking.

\section{INTRODUCTION}

The following article is presented within the framework of the "Digital tools for the acquisition of transversal skills and the application of the SDGs online", from the Educational Science Institute -ICEof the Universitat Politècnica de València.

In this case this work is focused on the analysis of the results obtained from this educational innovation from the subject Introduction to the Conservation and Restoration of golds and polychromies" of the Degree in Conservation and Restoration of Cultural Assets in Universitat Politècnica de València.

The ICT teaching experience in education is based on the adaptation that must take place in the university, taking into account the current communication and technology society. Given the large amount of teaching content, we should employ everyday languages that convey complex messages and offers the content a highly didactic, innovative and easy-to-understand aesthetic.

Faced with a hybrid-teaching scenario, the use of a versatile tool for the synthesis of contents has been proposed to facilitate the transfer of information.

The infographics have been prepared by both students and teachers, which generated abstraction to be expressed with a creative language that adapts to the codes familiar to both parties.

\subsection{Infographs as a teaching tool}

Infographics are presented as a very visual, attractive, didactic, dynamic, easily viewed and highly useful tool, because it contains complex content, in diagrams that follow current social visual codes and can provide a service applicable to many disciplines, if it focuses on the direction of information transfer in teaching.

As early as 2012, Carril et al. warned about the need for teacher training in the infographic field, conducting a study in which the fundamental basis was "In higher education there is a renewed interest in the design, production and use of multimedia resources. But its complexity in technical, graphic or pedagogical aspects can be problematic and discourage teachers interested in creating multimedia materials" [1]. 
We find some examples of infographics applied to teaching, which are usually intended to ease the conveying of a message, given that "the transmission of information based on the presentation of infographics can help to assimilate knowledge in a simple and direct way, being an useful teaching tool to improve knowledge" [2].

It is also important to note that the use of visual language facilitates making ideas visible, tangible and sequential, and encourages divergent collaborative thinking [3].

\subsection{Main goals}

It is intended to contribute to providing students with an analytical and synthetic vision of the subject contents, which will be worked separately with a visual language, so that they can develop their practical and critical thinking, and thus promoting efficient communication.

The teaching use of infographics has already been explored in previous cases where social transfer was carried out, especially in those that employ the Service Learning methodology, within the Final Degree Project and Final Master Project [3].

With this, the infographic design of content was proposed in order to promote dynamism and encourage creativity in the visual representation of student content, by enhancing the coexistence of multiple forms of representation with the use of ICT.

Later we will analyze the results obtained from the application of the infographics in teaching, with feedback given to the infographics of the teacher, and to those of the students.

The justification for the use of infographics as a teaching experience is given by the integration capacity of the tool, with a purpose of synthesis and abstraction, responding to a visual schematization of ideas and content.

\section{METHODOLOGY}

The methodology follows the parameters of the possibility of hybrid-teaching, being versatile in different teaching scenarios, and can be implemented in both face-to-face and online teaching.

\subsection{Planning phase}

In this first phase, among the teachers participating in the project, a series of specific objectives, content and didactic units will be proposed. For this, the peculiarities of each subject and the basic ideas that must be extracted in each of the didactic units are to be analyzed, to try achieve homogeneity in the infographic results.

During the planning phase, the specific objective of implementing the SDG goals through the use of ICT will be worked on. Likewise, it is intended to involve the specific objective that aims to work the general and specific competences of the subjects involved in this project.

\subsection{Implementation phase}

\subsubsection{Teaching staff infographic work}

In the first place, it is proposed that teachers provide examples of infographics (Figure 1), so that students are able to understand what is intended with the teaching strategy.

Students are offered the possibility to use free programs that will be made available. From exercises manuals to the use of more complex programs, these will remain absolutely free, to ensure an equal access to the technological tools.

To gain access to the realization of infographics, individualized research will be promoted, until the tool that is most suitable at an individual level is found. They will be able to use highly graphic online programs that offer extremely visual and attractive results. Examples of these are free applications such as Infogram $\AA$, Canva $\AA$, Data Wrapper $\AA$, iCharts $\AA$ or Piktochart $\AA$ among others. 
It is proposed to work on specific contents of the subject, firstly, by the teaching staff, and later, the students will be the ones who work on the general and specific competences of the subjects involved in this project.

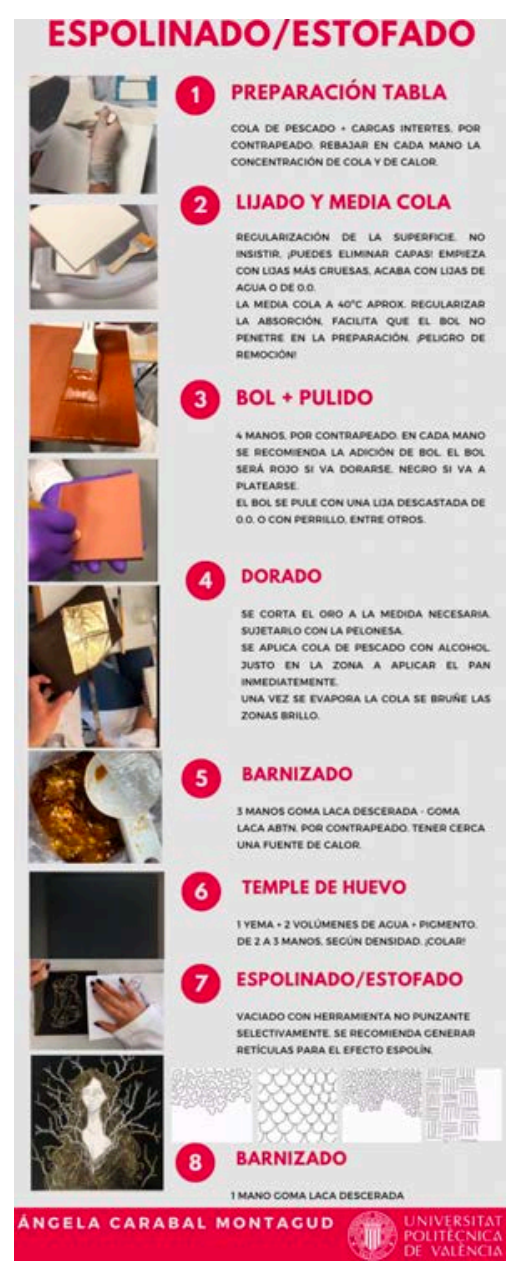

Figure 1. Infographic made by teachers for the synthesis of complex content.

\subsubsection{Student infographic work}

The development of the infographics by the students is proposed for each of the didactic units, or thematic units suggested by the teaching staff, for the subjects involved. The infographics for every unit will be presented at the beginning of each unit and evaluated at the end of each of the previously structured unit.

When preparing these infographics, the aim is to promote the use of different computer programs for each one of them, until they find the tool or tools with which they feel most comfortable in order to development the content. The use of several different programs for each of the topics to be developed will be positively valued.

This seeks to contribute to providing students with an analytical and synthetic vision of the contents of the subjects, which will be worked on separately with a visual language, so that they can develop their practical and critical thinking, and thus promoting efficient communication. 

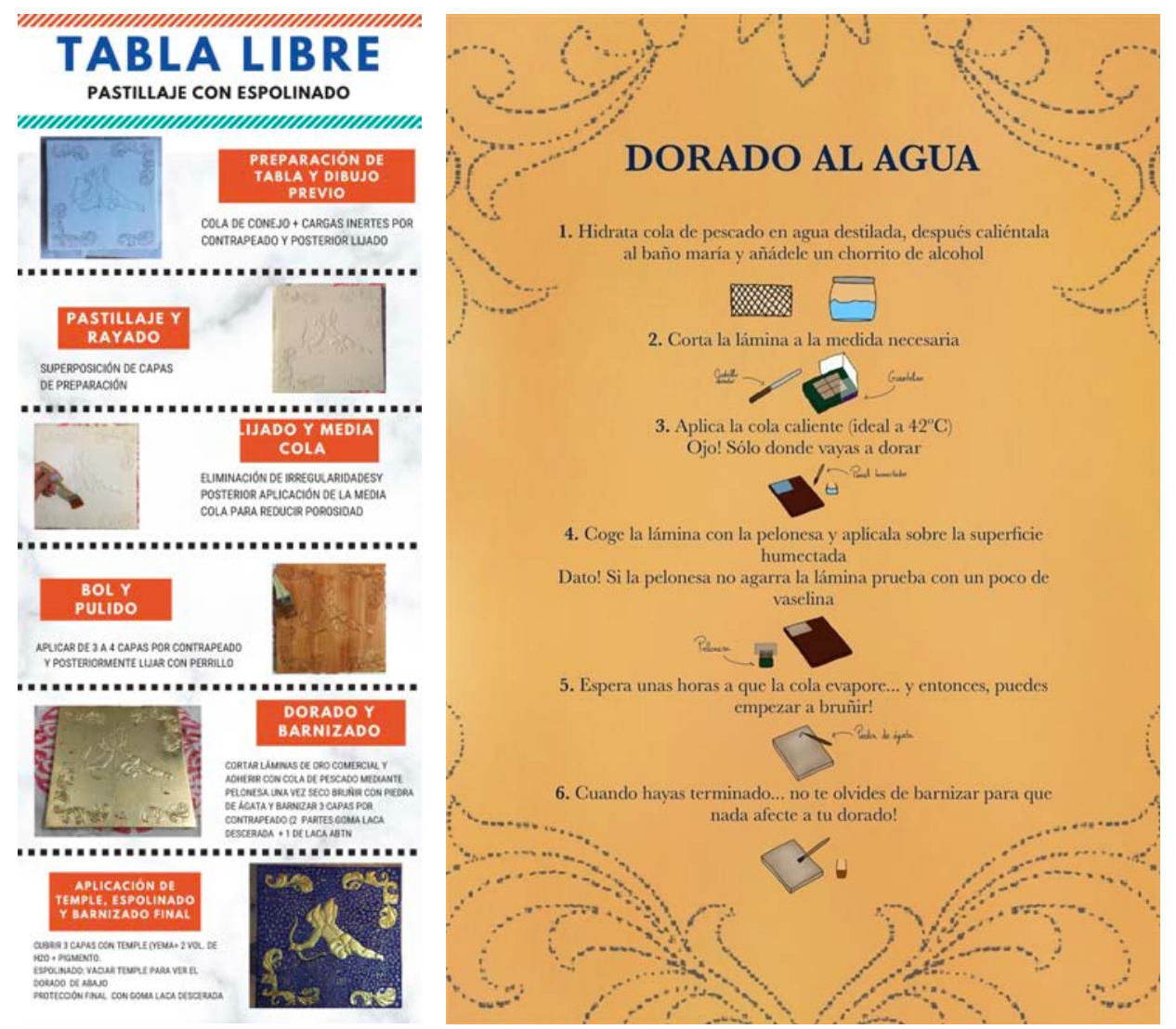

Figures 2 and 3. Infographic made by the students of the subject. Image 2 is the work of Andrea Gregori Cepedo, image 3 is by Naima Kientz Sánchez.

\section{RESULTS}

The results obtained have been measured objectively, through the systematic collection of data through three types of information sources. On the one hand, valuable information has been obtained during the presentation and subsequent debate, using the co-evaluation tool. Subsequently, control lists have been generated by the teaching staff to evaluate the acquisition of transversal competences and competences.

The opinion of teachers and pupils was valued. Finally, the students' experience has been evaluated, by giving them anonymous surveys, to which they have responded by analyzing various dimensions of the experience and whether or not it has been useful for their learning.

\subsection{Exhibition and debate}

A pooling of the work was proposed to generate a debate, which led to a team discussion about the results expected from the practice. According to Esteban García and Ortega Gutiérrez, "Using the debate can be a very useful strategy for the intellectual development of the student and for connecting university issues with social problems" [5].

In this way, not only individual work is promoted, but also the development of cooperative methodologies is activated, through exposure and debate, which are key tools for peer learning [6].

Co-evaluation is used as an assessment method, taking into account students' feedback. On the one hand, the teaching staff individually assessed the acquisition and understanding of theoretical-practical content. On the other hand, the students selected the infographic that best adapted to the suggested assessment scales, after a presentation was given, in which the selection criteria for the program chosen for the elaboration of the infographics was explained. 


\subsection{Evaluation of the results}

The teacher assessed the practice, by taking into account the transversal competences and competences that had been employed by every student. The transversal competences that have been used during this practice were: understanding and integration, innovation, and creativity.

In general, the teaching experience has helped students to synthesize content and the content progress has been superior to previous courses. This was possible because the effort to convey complex ideas with images and very little text has helped students to understand complex content, and enabled them to go much deeper into the matter.

Checklists were made for the evaluation. It was proposed to promote dynamism and foster creativity in the visual representation of student content, by enhancing the coexistence of multiple forms of representation.

\subsection{Evaluation of the teaching experience by the students}

In this case, the third evaluation tool has been the survey, through which a compilation of results of the level of student satisfaction has been collected, with the online survey tool SurveyMonkey ${ }^{\circledR}$ [7]. This survey has been answered by $98 \%$ of the students who carried out the practice, 34 responses, which will be distributed in percentages for the analysis of the results.

In general terms, overall satisfaction was very positive, since $96.1 \%$ of students considered this practice as integrating both theory and practice, in terms of usefulness of the practice.

Below we present the results obtained, evaluating the possibilities of infographics to transmit complex messages with a great capacity for synthesis, in addition to evaluating whether transversal skills, which were intended to be incorporated, were used, such as practical and critical thinking. In the same way, we evaluate the efficiency of visual language, with the employment of these tools, in addition to the time invested and the perception of usefulness of the tool.

\subsubsection{Assessment of synthesis capacity}

The ability to synthesize was one of the characteristics pursued with the present teaching experience, since on occasions, it is one of the most complex skills when the contents are of a high educational level.

When asked: "Have they helped you analyze in detail and synthesize content?" The result were very positive, because 96.15 of students have assessed that synthesis aspects have been worked on and $3.86 \%$ consider that they have not experienced any change when introducing this working methodology.

\section{¿Te han ayudado a analizar en detalle y sintetizar contenidos}

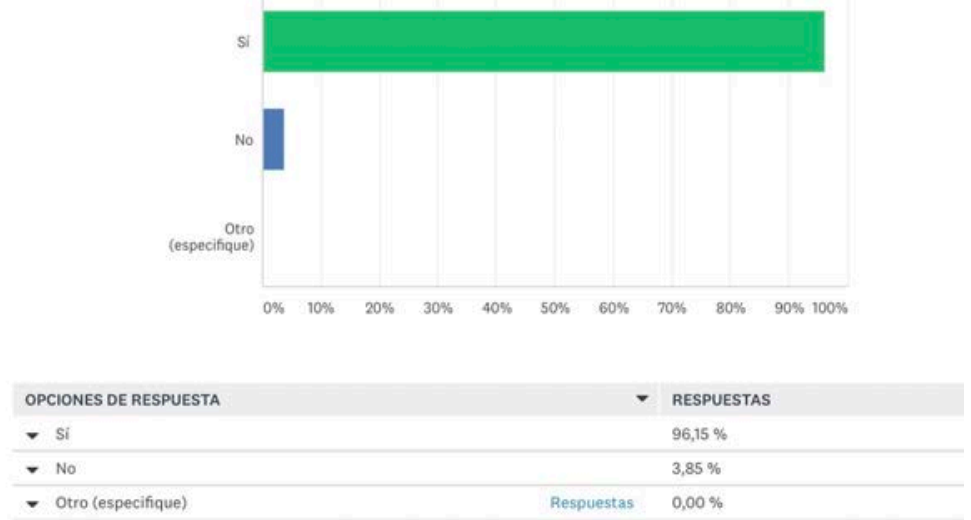

Figure 4. Results of the evaluation of the synthesis capacity. Survey with SurveyMonkey®. Source: self made.

\subsubsection{Assessment of transversal competence: practical and critical thinking}

Regarding the work and acquisition of the aforementioned transversal competence, when faced with the question: "Do you consider that creating infographics contributes to developing your practical and critical 
thinking?" $88.46 \%$ of students considered that they have worked this skill, while $7.69 \%$ declared that it has been indifferent to them and $3.85 \%$ considered that the use of infographics has not contributed to the development of their practical and critical thinking.

There is a large majority who considered that it has been a positive learning experience, which encouraged them to continue experimenting with this teaching tool, in search of new unknown aspects.

\section{¿Consideras que crear infografías contribuye a desarrollar tu pensamiento práctico y crítico?}

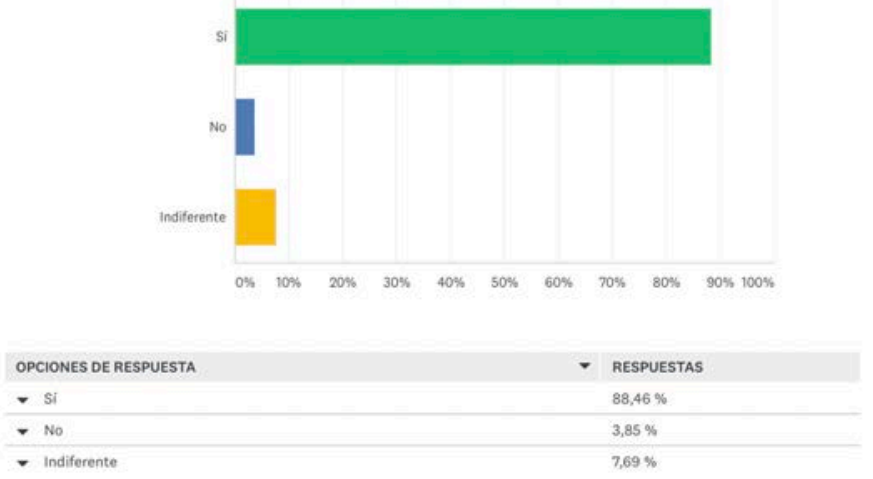

Figure 5. Results of the evaluation of practical and critical thinking. Survey with SurveyMonkey®.

Source: self made.

\subsubsection{Evaluation of infographics as efficient language}

Another question asked in the student survey was whether students believed that teaching infographics helped generate efficient language in a creative way.

Creativity is another strength of infographics, since each one of them offers a mode of representation, a diverse aesthetic, as well as the freedom to choose the program that best suits your needs. $88.46 \%$ affirmed that the experience has been positive on this point, paying special attention to creativity and inclusion in the modes of representation.

Creo que las infografías en la docencia ayudan a generar un lenguaje eficiente de manera creativa
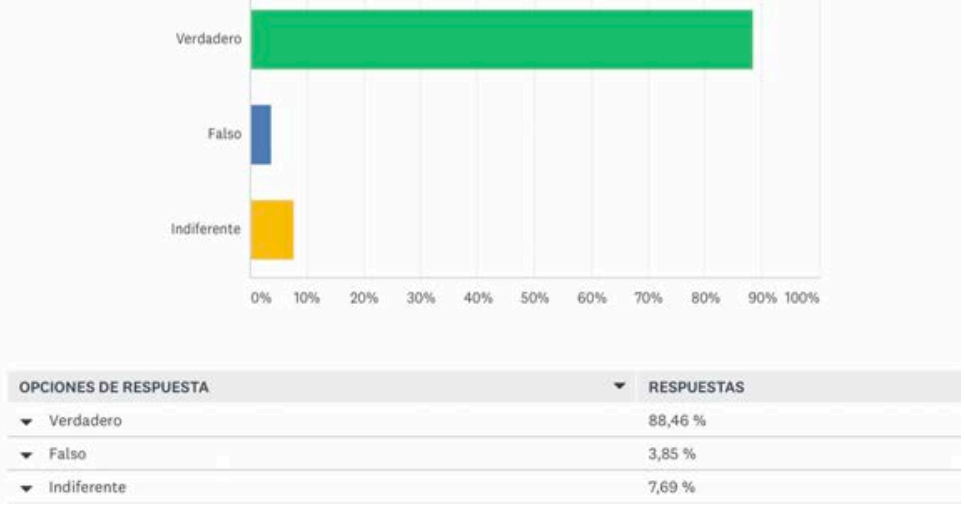

Figure 6. Results of the evaluation of infographics as efficient language. Survey with SurveyMonkey®. Source: self made.

\subsubsection{Evaluation of the investment of time by the students}

One of the aspects that is most valued when implementing teaching experiences, as methodological tools, is the use of time by students. 
On the one hand, it was intended that there would be an investment of time compatible with the study time of the subject, and on the other hand, it was not intended to increase the working hours of the students.

For this reason they have been asked if making the infographics for the subject has been a work overload.

A percentage of 80.77 of the students agreed that this has not generated additional work, in fact some of them included comments in which they valued that the time invested has been conducive to a better acquisition of content and skills.

However, $15.38 \%$ of students concluded that having to elaborate the infographics increased their workload.

Therefore, it is evident that the percentage of satisfaction with regard to work overload is positive.

\section{Hacer las infografias de la asignatura ha supuesto una sobrecarga de trabajo}

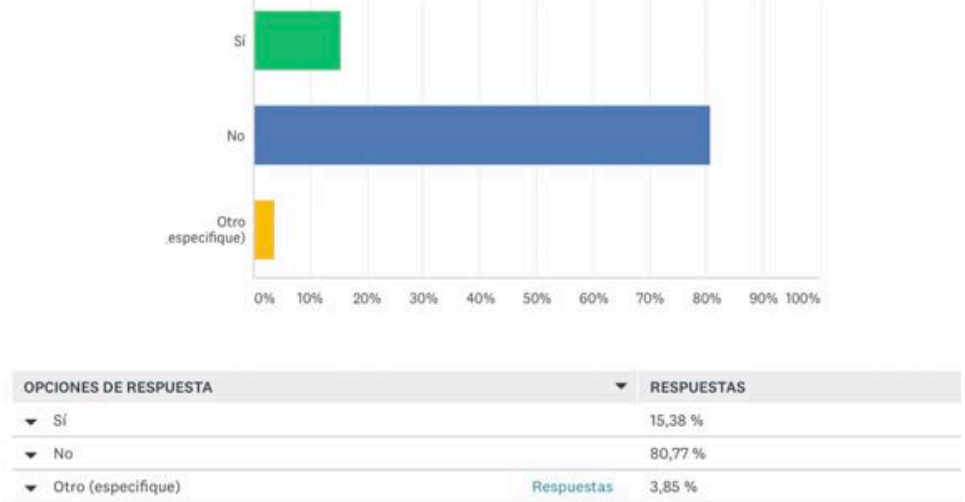

Figure 7. Results of the investment of time by the students. Survey with SurveyMonkey®. Source: self made.

\subsubsection{Evaluation of the usefulness of the use of infographics}

The students were asked if it was useful to use infographics as a teaching tool, in this case the results have been very positive, since $96.15 \%$ have valued the use of infographics as an academic strategy as being useful. This high percentage helps determine that, without appreciating it as a work overload, they appreciated the work done as part of their learning, integrating the contents in a useful way.

\section{¿Te ha resultado de utilidad el uso de infografías como herramienta} docente?

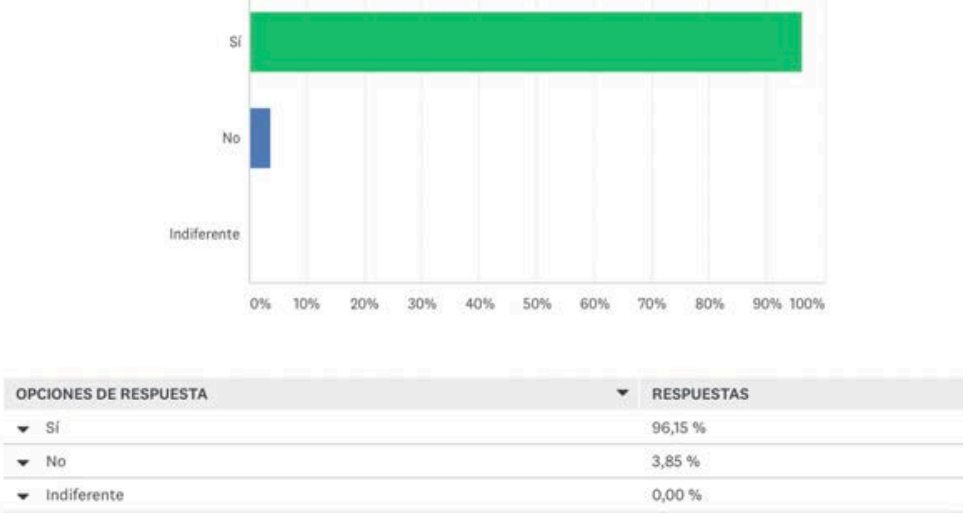

Figure 8. Results of the investment of time by the students. Survey with SurveyMonkey®. Source: self made. 


\section{CONCLUSIONS}

This article intends to analyze the results of the application of infographics as teaching tools.

On the one hand, the methods carried out in the classroom have been exposed to reach the conclusion that the results obtained have been useful to the students, without supposing a work overload, because they have served to set content for other evaluation tests and at the same time an efficient, visual and creative language has been developed.

On the other hand, practical and critical thinking, one of the most complex transversal competences within university teaching, has been conveniently worked on.

The main asset of the infographics was considered to be the synthesis capacity they offer, in the face of complex content, which has been evaluated by the students with $96.15 \%$, being a very positive evaluation, much higher than expected.

It is also noteworthy that the subject contents have advanced compared to previous courses, due to this reflective work. At the same time creativity has been worked on, obtaining a great diversity of results, completely different from each other. The diversity of works presented by students on the same subject and from the same teaching is remarkable. This leads us towards a convergence of university teaching focused on diversity.

With this, a new channel for effective understanding was generated, a mode of content transmission, in accordance with the current languages of the information and communication society in which we are immersed. All of it in the search for solutions to the face future teaching stages that will be encountered in the next courses.

The presented teaching methodology is transferable to any university disciplines in other centres or institutions, having specific practices designed for it.

\section{ACKNOWLEDGEMENTS}

To EICE "Digital tools for the acquisition of transversal skills and the application of the SDGs online", in the Educational Science Institute (Instituto de Ciencias de la Educación- ICE) in Universitat Politècnica de València, to provide a space in which to develop active and innovative methodologies.

\section{REFERENCES}

[1] Carril, P. C. M., Abeledo, E. J. F., \& Sanmamed, M. G. (2012). Necesidades formativas del profesorado universitario en infografía y multimedia. Revista de Investigación Educativa, 30(2), 303321.

[2] Olmedo Martín, E. (2018). Las infografías como herramienta docente y de impacto informativo. Retrieved from https://uvadoc.uva.es/bitstream/handle/10324/30220/TFG-MM1102.pdf?sequence=1\&isAllowed $=y$

[3] V. Santamarina, M.A. Carabal, M. de Miguel, B. de Miguel (2018) Collaborative visual language for the development of innovative ideas, EDULEARN18 Proceedings, pp. 535-543.

[4] Carabal Montagud, M. A., Taroncher Ballestero, J., Santamarina Campos, V., \& Esgueva López, M. V. (2021). Las infografías como herramienta de transferencia social. In Proceedings INNODOCT/20. International Conference on Innovation, Documentation and Education. pp. 719727. Editorial Universitat Politècnica de València.

[5] Esteban González, L., Ortega Gutiérrez, J. (2017). "El debate como herramienta de aprendizaje" en Jornada de Innovación e Investigación docente 2017. Universidad de Sevilla. 48-56.

[6] Carabal Montagud, M. A., Santamarina Campos, V., Esgueva López, M. V., \& Vicente Palomino, S. (2020). Cooperative learning and brainstorming as didactic strategies in conservation and restoration of cultural assets. Retrieved from https://riunet.upv.es/handle/10251/152763

[7] Survey Monkey (2020). Infografías en la docencia. Retrieved from https://es.surveymonkey.com/r/S5QTN7Z 